\title{
Anthropocène et viroses émergentes
}

\section{Anthropocene and Emerging Viral Diseases}

\section{Chastel}

Reçu le 6 avril 2016; accepté le 6 avril 2016

(C) Société de pathologie exotique et Lavoisier SAS 2016

Résumé Un rapprochement est proposé entre le concept d'anthropocène, ère géologique nouvelle centrée sur l'Homme et son emprise grandissante sur l'environnement depuis le milieu du siècle dernier, et l'émergence accrue de virus nouveaux, pathogènes pour l'Homme et pour l'animal.

Mots clés Anthropocène - Activités humaines ·

Modifications de l'environnement · Viroses émergentes sida, l'extension américaine du virus West Nile, les épidémies du monkeypox, du SRAS, du MERS, l'invasion de l'océan Indien, puis de la planète par le virus Chikungunya et l'extension inopinée d'Ebola à l'Afrique de l'Ouest. Enfin, Zika, un virus africain, a d'abord gagné la Micronésie, avant de toucher l'ensemble du monde, y exerçant ses effets délétères sur le système nerveux central humain et l'enfant à naître.

\section{Un rapprochement qui s'impose avec l'anthropocène}

Alors que les activités humaines récentes se traduisent sur le plan géologique par des modifications stratigraphiques distinctes de celles de l'Holocène [7], celles-ci sont aussi responsables des profondes modifications associées à l'émergence de virus nouveaux, comme le montre le Tableau 1.

Puis, le génome de ces virus ADN (monkeypox) et surtout ARN (tous les autres virus émergents), en évoluant plus ou moins rapidement, permettrait leur « succès émergentiel » $[1,2]$ dans un environnement favorable, sauvage (fièvres hémorragiques) ou urbain (fièvre jaune, dengue, Chikungunya, Zika).

\section{Conclusion}

L'Homme piétine allègrement la Terre depuis le Néolithique supérieur avec l'apparition de l'agriculture, de l'irrigation, des premières domestications (chien, bovins), de la métallurgie, puis l'édification des grandes cités-États au MoyenOrient et sur l'Indus. Cette emprise n'a fait que s'accentuer au cours des siècles et a coïncidé, à partir des années 1950, avec l'émergence accrue de virus nouveaux, pathogènes pour l'Homme et pour l'animal. Il ne s'agit pas d'une coïncidence, et le concept d'anthropocène rend bien compte de ce lien. 
Tableau 1 Anthropocène et viroses émergentes : quelques exemples / Anthropocene and emerging viral diseases: some examples.

\begin{tabular}{|c|c|c|}
\hline Activités humaines comportements & Conséquences & Émergences ou réémergences \\
\hline Agriculture intensive & $\begin{array}{l}\text { Contacts étroits avec des rongeurs } \\
\text { sauvages }\end{array}$ & $\begin{array}{l}\text { - Fièvre hémorragique d'Argentine } \\
\text { (virus Junin) } \\
\text { - Fièvre hémorragique du Venezuela } \\
\text { (virus Guanarito) }\end{array}$ \\
\hline $\begin{array}{l}\text { Consommation alimentaire d'animaux } \\
\text { sauvages }\end{array}$ & $\begin{array}{l}\text { Infections humaines en Chine par des virus } \\
\text { de Civette de l'Himalaya, blaireaux, } \\
\text { chiroptères, etc. }\end{array}$ & $\begin{array}{l}\text { - SRAS dû à un coronavirus nouveau } \\
\text { (Sars-Cov) }\end{array}$ \\
\hline $\begin{array}{l}\text { Déforestation, ouverture de grands axes } \\
\text { routiers en milieu tropical }\end{array}$ & $\begin{array}{l}\text { Accès à la « viande de brousse ": } \\
\text { rongeurs, antilopes forestières, singes }\end{array}$ & - Ebola, monkeypox, retrovirus simiens \\
\hline $\begin{array}{l}\text { Déstructuration des services de santé : } \\
\text { catastrophes naturelles, conflits armés }\end{array}$ & $\begin{array}{l}\text { Arrêt de la surveillance épidémiologique } \\
\text { et des vaccinations de masse, relâchement } \\
\text { de l'hygiène publique et hospitalière }\end{array}$ & $\begin{array}{l}\text { - Poliomyélite, dengue, fièvre jaune } \\
\text { et autres viroses transmises } \\
\text { par des moustiques }\end{array}$ \\
\hline Élevages intensifs : porcs, poulets & $\begin{array}{l}\text { Concentration des animaux sur de faibles } \\
\text { surfaces, contacts avec des chiroptères }\end{array}$ & $\begin{array}{l}\text { - Encéphalite à virus Nipah, grippes } \\
\text { aviaires, H1N1, H7N3, H7N9 }\end{array}$ \\
\hline Grands barrages en milieu tropical & $\begin{array}{l}\text { Extension des zones inondées, prolifération } \\
\text { des moustiques }\end{array}$ & - Fièvre de la Vallée du Rift, fièvre jaune \\
\hline $\begin{array}{l}\text { Pratiques sexuelles à risque, tourisme } \\
\text { sexuel }\end{array}$ & $\begin{array}{l}\text { Propagation chez les homosexuels } \\
\text { mâles des VIH } 1 \text { et VIH 2, dérivés } \\
\text { de retrovirus simiens }\end{array}$ & $\begin{array}{l}\text { - Sida : émergence et entretien } \\
\text { de l'endémie }\end{array}$ \\
\hline Trafic aérien international & $\begin{array}{l}\text { Transport à distance de sujets infectés } \\
\text { de façon apparente ou inapparente [5] }\end{array}$ & $\begin{array}{l}\text { - Franchissement de l'Atlantique } \\
\text { par le virus West Nile. Diffusion mondiale } \\
\text { du sida, de Chikungunya et de Zika }\end{array}$ \\
\hline Trafic d'animaux sauvages & $\begin{array}{l}\text { Importation dans des régions } \\
\text { géographiques indemnes de virus; } \\
\text { contamination de la faune sauvage locale }\end{array}$ & $\begin{array}{l}\text { - Importation, en 2003, du monkeypox } \\
\text { aux États-Unis }\end{array}$ \\
\hline $\begin{array}{l}\text { Transfusion sanguine, transplantation } \\
\text { d'organes ou de tissus (y compris } \\
\text { la cornée) }\end{array}$ & $\begin{array}{l}\text { Introduction accidentelle dans l'organisme } \\
\text { du receveur de virus provenant } \\
\text { d'un donneur infecté }\end{array}$ & $\begin{array}{l}\text { - Sida, hépatites virales, retrovirus HTLV, } \\
\text { virus de la dengue, Chikungunya et Zika }\end{array}$ \\
\hline $\begin{array}{l}\text { Urbanisation galopante, souvent } \\
\text { anarchique }\end{array}$ & $\begin{array}{l}\text { Prolifération des rats, des moustiques } \\
\text { et des phlébotomes }\end{array}$ & $\begin{array}{l}\text { - Fièvre jaune, Chikungunya, Toscana, } \\
\text { autres phlebovirus }\end{array}$ \\
\hline
\end{tabular}

\section{Références}

1. Chastel C (2000) Émergences virales chez l'homme et réussite émergentielle. Virologie 4:273-9

2. Chastel C (2000) Emergential success: a new concept for a better appraisal of viral emergences and reemergences. Acta Virol 44:375-6

3. Chastel C (2006) Virus émergents. Vers de nouvelles pandémies ? Vuibert-ADAPT-SNES Ed, $316 \mathrm{p}$

4. Chastel C (2007) Les virus bougent, périls planétaires. Bull Acad Natl Med 191:1563-77

5. Duong V, Lambrechts L, Paul RE, et al (2015) Asymptomatic humans transmit dengue virus to mosquitoes. Proc Natl Acad Sci USA 112:14688-93
6. Masson-Delmotte V (2016) Le terme « Anthropocène » a le mérite de pointer la responsabilité de l'homme. La Recherche 509:31

7. Waters CN, Zalasiewicz J, Summerhayes C, et al (2016) The Anthropocene is functionally and stratigraphically distinct from the Holocene. Science 351:aad2622

\section{Commentaire de P. Gazin}

pierre.gazin@ird.fr

Il est gênant d'associer grands barrages et extension de viroses transmises par des Aedes. Ces moustiques ne sont pas liés aux extensions de grandes zones d'eau de surface. On pourrait souligner l'importance des rapides échanges 
humains intercontinentaux par voie aérienne. Ce sont plusieurs centaines de millions d'humains qui actuellement voyagent au cours d'une année d'un continent à un autre.

\section{Commentaire de V. Deubel}

deubelvincent@gmail.com

Dr Gazin, vous avez raison pour le rôle des transports aériens intercontinentaux pour l'introduction de nouveaux virus : personnes virémiques ou animaux infectés ou moustiques infectés (comme l'indique dans sa note le Dr Claude Chastel à propos du virus West Nile). Pour ce qui est du rôle des barrages dans l'apparition de viroses, le Dr Chastel fait sûrement allusion aux barrages d'Assouan et de Diama qui ont été à l'origine d'épidémies de rift valley fever (augmentation des moustiques Aedes aegypti, mais surtout concentration d'animaux et d'humains aux points d'eau).

Sur l'article de Claude Chastel

La propagation d'arbovirus dans certaines régions peut parfois être associée à l'explosion de vecteurs moustiques comme cela a été décrit pour le virus West Nile (sécheresse de 1999 à New York et piscines inutilisables favorisant la présence de très nombreux Culex), pour les virus de la dengue et de la fièvre jaune (abandon de la lutte antivectorielle en Amérique du Sud et propagation du moustique A. aegypti ) et pour le virus Chikungunya (importation aux États-Unis en 1987 dans des pneus en provenance d'Asie du moustique tigre Aedes albopictus, puis propagation en Amérique du Sud et dans les Caraïbes).

\section{Commentaire de B.A. Gaüzere}

bernard.gauzere@chu-reunion.fr

- Population humaine : il conviendrait de mettre en perspective avec la sédentarisation de l'Homme au début du Néolithique, l'accroissement de la population mondiale. Il a fallu trois millions d'années pour atteindre un milliard d'Hommes sur Terre, vers 1800, puis un seul siècle pour passer d'un à deux milliards (vers 1925). Et depuis 1960, période mentionnée par l'auteur, la population humaine a encore doublé, passant de trois à six milliards pour s'établir en 2016 à plus de sept milliards. Un tel accroissement, une telle promiscuité, de tels déplacements autour de la planète favorisent-ils la diffusion des virus?
- Réduction de la biodiversité liée aux activités humaines : ne s'agit-il pas d'un autre facteur de l'acquisition des virus (exemple : El typho negro en Bolivie) ?

\section{Commentaire de F. Moutou}

francoismoutou@orange.fr

Émergences et anthropocène

La notion d'anthropocène est débattue quel que soit le bien-fondé du constat globalement préoccupant de l'impact actuel de l'espèce humaine sur l'environnement mondial. Certains suggèrent que cet impact existe depuis qu'Homo sapiens existe, c'est-à-dire depuis environ 200000 ans et qu'ensuite il ne s'agit que d'une question de degré [1]. Un paramètre évidemment essentiel est celui de la démographie [3]. Si le premier milliard d'habitants de la planète semble atteint vers 1800, l'explosion démographique qui suit n'a pas d'équivalent. Le siècle 1950-2050 verra probablement la population mondiale tripler, peut-être quadrupler. Le milieu du $\mathrm{xx}^{\mathrm{e}}$ siècle étant également ce que certains retiennent comme le début de l'anthropocène, on peut y voir soit une confirmation, soit une coïncidence, ce qui ne change rien aux conséquences.

En épidémiologie, les notions de seuil étant importantes, on peut comprendre que des phénomènes encore inconnus ou non observés jusqu'à présent puissent émerger dans un tel contexte. D'un côté, il existe des mégalopoles de plus de 10 millions d'habitants et, de l'autre, il reste peu d'espaces terrestres non visités par des humains. Les probabilités de nouvelles rencontres et de nouvelles adaptations micro-organismes-espèce humaine ne peuvent que croître et surtout devenir apparentes, qu'il s'agisse de virus, bactéries ou parasites au sens le plus large. La globalisation fait effectivement le reste. Les avions transportent plus de 3 milliards de passagers par an pour une population mondiale estimée à 7,3 milliards en 2015 [2]. Cette tendance devrait se poursuivre pendant encore au moins quelques décennies. Les équipes pluridisciplinaires d'épidémiologie ont de beaux jours devant elles.

\section{Références}

1. Harari YN (2015) Sapiens. Une brève histoire de l'humanité. Albin Michel, Paris, $507 \mathrm{p}$

2. Moutou F (2015) Des épidémies, des animaux et des hommes. Le Pommier, Paris, $383 \mathrm{p}$

3. Roberts L (2011) 9 billions ? Science 333:540-3 